\title{
ENDOSCOPIC LASER CORDOTOMY FOR BILATERAL RECURRENT PARALYSIS - COMMENTS ON A CLINICAL CASE
}

\author{
Mihail TUŞALIU ${ }^{1,2} \bowtie$, Lavinia G. SAVA ${ }^{1}$, Alexandru PANFILOIU ${ }^{1}$, Tatiana DECUSEARĂ ${ }^{1}$, \\ Alexandra GULIGĂ ${ }^{1}$, Cristina M. GOANȚĀ ${ }^{1,3}$, Cristian IONIȚÁ${ }^{1}$, Vlad A. BUDU1,2 \\ ${ }^{1}$ Institute of Phonoaudiology and Functional ENT Surgery „Prof. Dr. D. Hociotă“, Bucharest, Romania \\ ${ }^{2}$ University of Medicine and Pharmacy „Carol Davila“, Bucharest, Romania \\ ${ }^{3}$ Clinical Emergency Hospital „Sf. Pantelimon“, Bucharest, Romania
}

Received 02 Apr 2018, Accepted 29 May 2018

\section{Abstract}

Introduction. Bilateral recurrent paralysis treatment has changed in the last decades as various procedures have been developed in order to superiorly preserve the functions of the larynx. For life-threatening situations tracheotomy remains the treatment of choice.

Case presentation. In this article we present the case of a 64 year-old patient, known with bilateral recurrent paralysis, who presented to our clinic with mild to moderate inspiratory dyspnea on effort. The endoscopic examination revealed the vocal folds in paramedian position, with a respiratory space reduced by $80 \%$. We performed an endoscopic posterior cordotomy, also known as Kashima procedure.

Conclusions. Kashima procedure or endoscopic laser posterior cordotomy is a preferred technique with better long term outcomes. It prevents the necessity of tracheotomy and improves the quality of life of the patient, by both widening the airway and preserving phonation.

Keywords: bilateral recurrent paralysis, laser cordotomy.

\section{RÉSUMÉ}

Chordotomie endoscopique au laser pour une paralysie récurrente bilatérale - Observations sur un cas clinique.

Introduction. Le traitement de la paralysie récurrente bilatérale a changé au cours des dernières décennies, car divers procédés ont été mis au point pour préserver de façon optimale les fonctions du larynx. Pour les situations potentiellement mortelles, la trachéotomie reste le traitement de choix.

Présentation du cas. Dans cet article, nous présentons le cas d'un patient de 64 ans, connu avec paralysie récurrentielle bilatérale, qui s'est présenté à notre clinique avec une dyspnée inspiratoire légère à modérée. Lexamen endoscopique a révélé les replis vocaux en position paramédiane, avec un espace respiratoire réduit de $80 \%$. Nous avons réalisé une cordotomie postérieure endoscopique, également appelée procédure de Kashima. Conclusion. Le procédé de Kashima ou la chordotomie endoscopique au laser est une technique préférentielle aux meilleurs résultats à long terme. Il prévient la nécessité de la trachéotomie et améliore la qualité de la vie du patient, tant en élargissant les voies respiratoires, qu'en préservant la phonation.

Mots-clés: paralysie récidivante bilatérale, chordotomie au laser. 


\section{INTRODUCTION}

Bilateral recurrent paralysis is a pathology defined by the immobilization of both vocal folds, which causes a significant decrease of the glottis and has an important impact on the quality-of-life of the patient, as it affects the respiratory and the phonatory function of the larynx. Etiology includes infectious causes, inflammatory conditions, larynx trauma, neurologic diseases, malignancies, iatrogenic causes, while a percentage remains with an unknown cause ${ }^{1}$. Total thyroidectomy is the most common iatrogenic cause of bilateral recurrent palsy, though it is not a frequent situation, with a 0.5 percentage in specialized centers ${ }^{2,3}$.

Larynx innervation is provided by the superior laryngeal nerve, which innervates the external cricothyroid muscle and the inferior or recurrent laryngeal nerve, which supplies all the intrinsic laryngeal muscles. Injury to both recurrent nerves causes the vocal folds to remain in a paramedian position, called posticus paralysis, explained by the functionality of the external adductor muscle and the predominance of the only abductor muscle, the posticus or cricoarytenoid muscle 4 . The paramedian position of the vocal folds grants the patient with a satisfying voice, but causes an important decrease in the respiratory space, which can aggravate under certain factors, such as physical effort, emotional stress, respiratory tract infections and induce an acute respiratory distress.

Symptomatology of bilateral recurrent palsy includes dyspnea of different grades, more obviously during physical effort and sleep, decrease in speech volume, hoarseness and dry cough ${ }^{4}$. Evaluation of bilateral recurrent paralysis of the patient must include an endoscopic examination of the larynx, in order to decide the side of surgery ${ }^{5}$.

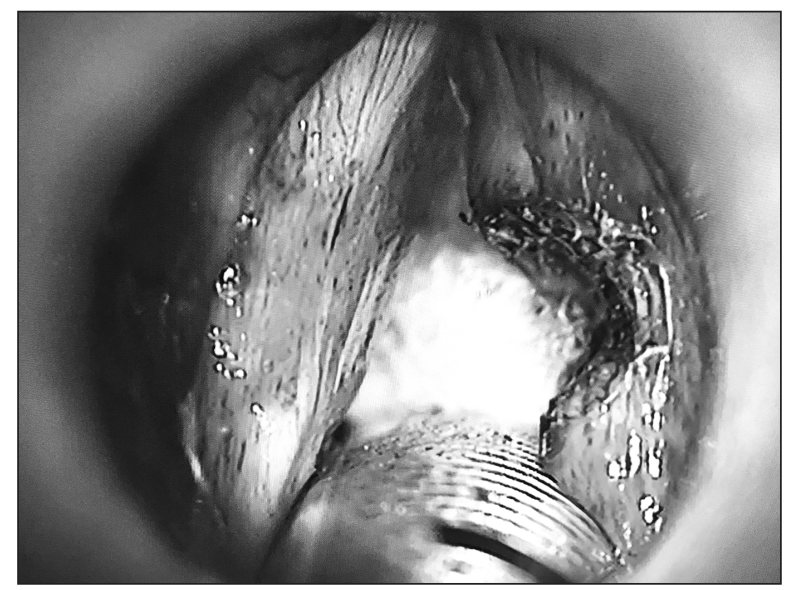

Figure 1. Intraoperative aspect.

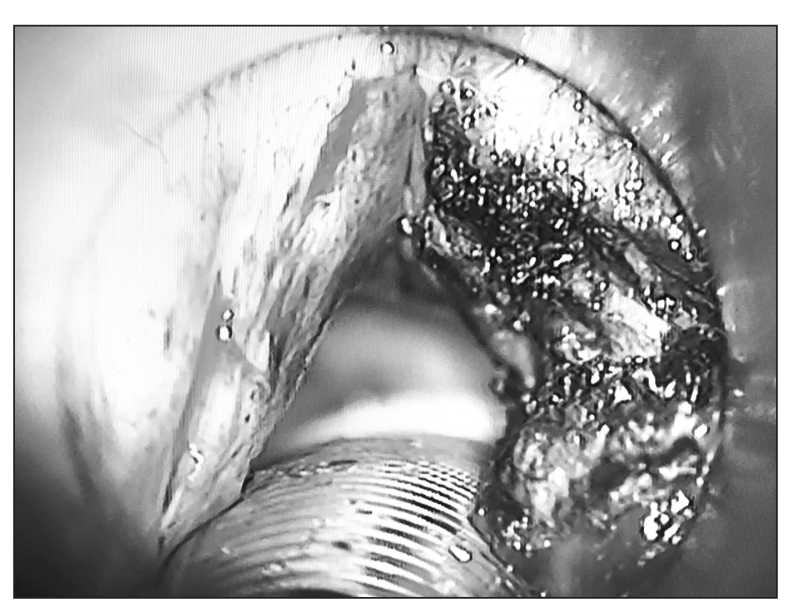

Treatment in bilateral vocal fold paralysis is most frequently surgical. There have been developed several surgical procedures, using both an external and endoscopic approach, since 1922, when Jackson described the resection of the vocal fold and ventricle for vocal cords palsy. Therapy aims to improve glottis area, preserve airway protection and maintain a favorable voice ${ }^{6}$. Surgical options include partial or total arytenoidectomy, lateralization of the vocal fold by suture and posterior transverse cordotomy. Before endoscopic and laser technology was developed, most methods required prophylactic tracheotomy, which resulted in a poor voice. Tracheotomy remains the treatment of choice for most patients who present acute respiratory distres ${ }^{7,8}$. Kashima procedure or laser endoscopic posterior cordotomy, described in 1989 by Dennis and Kashima, is one of the most preferred surgical techniques as it improves the posterior glottis area. Posterior glottis represents $50-65 \%$ of the total glottis, which explains why this approach has a better outcome on the air flow ${ }^{6,9}$. This procedure preserves the anterior glottis, which ensures good phonation and also has low aspiration risk ${ }^{8}$.

\section{Case presentation}

The authors present the case of a 64 year-old female patient, known with bilateral recurrent paralysis after total thyroidectomy for multinodular goiter performed one year prior to presentation, who presented to our clinic for mild to moderate inspiratory dyspnea on effort. From her past medical history we retain left invasive ductal carcinoma for which she underwent conservative surgery, chemotherapy and radiotherapy, hypertension, diabetes mellitus type 2 insulin dependent.

Clinical examination reveals hoarseness, decrease in speech volume and mild shortness of breath 


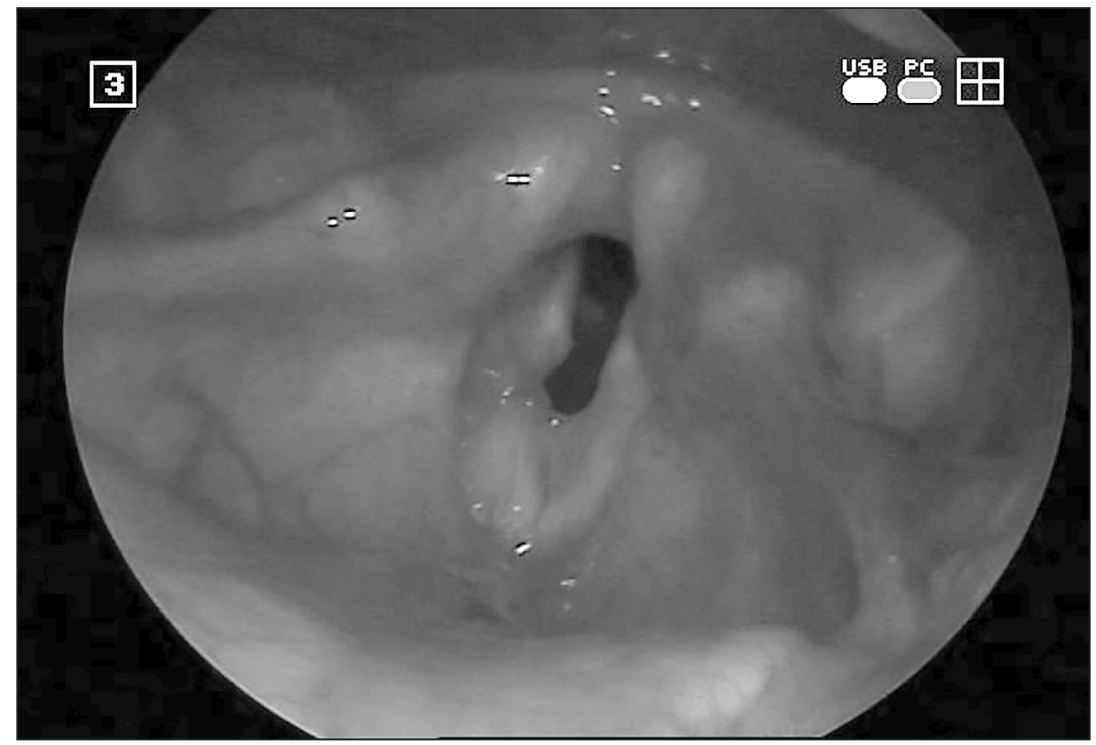

Figure 2. One month postoperative aspect.

while speaking. Nasal fiberoptic endoscopy showed vocal folds in paramedian position, glottis reduced by $80 \%$ (approximately $2-3 \mathrm{~mm}$ ). Laboratory results did not show any modifications.

Under general anesthesia, we performed a right posterior endoscopic cordotomy, at $2 \mathrm{~mm}$ anteriorly of the vocal process, protecting the arytenoid cartilage. By exposing the posterior glottis and using a $\mathrm{CO} 2$ laser with low powers $(2-4 \mathrm{~W})$ we performed an incision of the vocal ligament and the vocal muscle in the posterior third of the right vocal fold. The incision was extended laterally to the thyroid cartilage, creating a convenient respiratory area (Figure 1). The patient received intravenous antibiotics, steroid anti-inflammatory drugs and had a positive general and local evolution.

Follow - up at one month showed normal healing, with the presence of fibrin deposits on the vocal fold. Respiratory area has been improved by approximately 30\% (5-6 $\mathrm{mm})$ and the patient did not present dyspnea at rest or at medium effort (Figure 2).

\section{Discussion}

All treatment options for bilateral vocal fold paralysis aim to ensure the air passage, protection of the larynx, normal swallowing without aspiration and a convenient voice. The main purpose is to relieve the airway obstruction, because the abductor muscle function is lost. Tracheostomy assures a more efficient airway and is most frequently opted for emergencies, but has a high social impact for the patient and is hardly accepted as a long term solution ${ }^{8}$. Surgical techniques which approach the arytenoids and ventricles by using CO2 laser have a higher risk of postoperative granuloma and may require reintervention ${ }^{9}$. The phonatory function is better preserved by using these procedures, but they have higher postoperative aspiration rates 9 . A perfect procedure does not exist for bilateral recurrent paralysis with adduction. All modern techniques target two functions of the larynx, phonation and breathing, usually improving the airway to the detriment of the voice, which most often has a lower quality after surgery. Endoscopic CO2 laser posterior cordotomy or Kashima procedure is a preferred technique as it is minimally invasive and preserves the anterior vocal folds, it does not require temporary tracheotomy and is a fast procedure, so it can be performed on patients who cannot sustain long anesthesia? ${ }^{7}$ Kashima procedure offers a satisfactory compromise between phonation and breathing. The use of a surgical microscope with $\mathrm{CO} 2$ laser has the advantage of a precise technique, a better control of hemostasis, faster healing process and a shorter hospitalization".

In our case, we opted for surgical management because of the clinical presentation of our patient. Though she presented satisfactory breathing at rest, she accused aggravating episodes at effort and at low temperatures. The therapeutic plan must meet the patient's needs, social standards and the possibility of an active life. After that, we evaluated the glottis aperture we decided for an unilateral endoscopic posterior cordotomy. Many studies report a temporary impairment of the voice after laser surgery ${ }^{8}$. In our case the patient described a comparable voice quality as before surgery. 
After surgery, the new surgically created respiratory area may decrease by the development of a scar at the incision site. If needed, superior results for the respiratory aperture can be obtained by performing an incision extended to the anterior commissure on the same vocal fold, with the partial resection of the thyroarytenoid muscle on the same side. Unilateral cordotomy acquires better voice quality and in need, it offers the possibility of reintervention with endoscopic medial arytenoidectomy or cordotomy of the contralateral vocal fold ${ }^{10,11}$. Revision surgery for postoperative granulomas or scars must be taken into consideration if needed.

\section{Conclusions}

Bilateral recurrent paralysis is a problematical condition in otolaryngology as it affects most functions of the larynx. Opting for a treatment for any patient with bilateral recurrent paralysis represents a compromise between airway and voice quality. Kashima procedure or endoscopic posterior cordotomy is a safe procedure which significantly improves the glottis area, conserves phonation and avoids tracheotomy.

\section{Compliance with Ethics Requirements:}

„The authors declare no conflict of interest regarding this article"

"The authors declare that all the procedures and experiments of this study respect the ethical standards in the Helsinki Declaration of 1975, as revised in 2008(5), as well as the national law. Informed consent was obtained from all the patients included in the study"

\section{References}

1. Bhattacharyya AK, Stimpson P, Sen P. Laryngology - Head and Neck Surgery Series, 2014, Thieme; 161-172.

2. Kwak S, Lim T, Oh Y, et al. Bilateral recurrent laryngeal nerve palsy in a patient undergoing consecutive thyroid operations. Korean J Anesthesiol 2013; 65(Suppl 6); S36-S37.

3. Zabrodsky M, Boucek J, Kastner J, et al. Immediate revision in patients with bilateral recurrent laryngeal nerve palsy after thyroid and parathyroid surgery. How worthy is it? Acta Otorhinolaryngol Ital, 2012; 32(4); 222-228.

4. Becker W, Naumann HH, Pfaltz CR. Ear, Nose and Throat Diseases, $3^{\text {rd }}$ Edition, 2008; 402-408.

5. Hachiya A, Nita LM, Chrispim FS, et al. Cordotomy and partial arytenoidectomy for the treatment of bilateral vocal cord paralysis in adduction. International Archives of Otolaryngology, 2007; 11(3); 311-316.

6. Issac ME. Effect of Kashima's surgery in bilateral abductor vocal cord palsy. Int J Phonosurg Laryngol, 2017; 7(1); 10-12.

7. Raoa R, Shenoya V, Prasada V, et al. A comparative study of laser posterior cordotomy and vocal cord lateralization. Egyptian J of Ear, Nose, Throat and Allied Sciences, 2015; 16(3); 255-258.

8. Asik MB, Karasimav $\mathrm{O}$, Birkent $\mathrm{H}$, et al. Impact of unilateral carbon dioxide laser posterior transverse cordotomy on vocal and aerodynamic parameters in bilateral vocal fold paralysis. The Journal of Laryngology and Otology, 2016; 130; 373-379.

9. Ludlow CL, Mann EA. Ballenger's Otorhinolaryngology Head and Neck Surgery, 16th Edition, 2003; Williams \& Wilkins; 1233-1254

10. Bosley B, Rosen CA, Simpson CB, et al. Medial arytenoidectomy versus transverse cordotomy as a treatment for bilateral vocal fold paralysis. The Annals of Otology, Rhinology and Laryngology, 2005; 114(12); 922-926.

11. Özdemir S, Tuncer Ü, Tarkan Ö, et al. Carbon dioxide laser endoscopic posterior cordotomy technique for bilateral abductor vocal cord paralysis - a 15-year experience. JAMA Otolaryngology - Head and Neck Surgery, 2013; 139(4); 401-404. 